\title{
Colonoscopic Yield in Patients with Lower Gastrointestinal Bleeding - A Study of 309 Cases
}

\author{
Madhusudan Saha ${ }^{* 1}$, Md Anisur Rahman², Mohammad Zakaria ${ }^{3}$, \\ Musammat Aklima Akter Hely ${ }^{4}$, Nasrin Aktar ${ }^{5}$, Habib Ullah Abir ${ }^{6}$
}

\begin{abstract}
:
Introduction: This retrospective study was done to see colonoscopic yields in patients presenting with lower gastrointestinal bleeding. Materials \& Methods: Reports of patients undergoing colonoscopy due to bleeding per rectum were retrieved from endoscopy records. Patients' particulars and colonoscopic findings were recorded in a data sheet. Analysis was done using SPSS 20 version. Results: A total of 309 patients (male 211 (68.3\%) and female 98 (31.7) with mean age 40.3 years \%)) were included in this study. According to colonoscopic yield, causes of LGIB were haemorrhoids $137(44.33 \%)$, rectal and colonic growth 58(18.77\% ) rectal and colonic polyps 54 (17.47\%), anal fissure $38(12.29 \%)$, proctitis $18(5.82 \%)$, colitis $18(5.82 \%)$, ileal ulcer and ileitis 34(11.0\%). Colorectal growth was more common among patients age 26 to 60years. Among male rectal growth was slightly higher than female. Conclusion: Lower gastrointestinal bleeding is more common among males. Commonest cause of LGIB are internal haemorrhoids, rectal growth, rectal and colonic polyps and anal fissure. Colorectal neoplasm, proctitis, colitis and ileal inflammation and ulcers constitute small part.
\end{abstract}

Key words: Colonoscopy, Lower GI bleeding.

Number of Tables: 02; Number of References: 20; Number of Correspondences: 05.

*1. Corresponding Author: Dr. Madhusudan Saha MBBS, DNM, MD

Professor

Department of Gastroenterology

North East Medical College, South Surma, Sylhet.

Email: madhunibedita@gmail.com;

Mobile: +880171367847

2. Dr. Md Anisur Rahman, MBBS, DEM

Assistant Professor

Department of Gastroenterology

North East Medical College, South Surma, Sylhet.

3. Dr. Mohammad Zakaria, MBBS

Assistant Registrar

Department of Gastroenterology

North East Medical Collge, South Surma, Sylhet.

4. Dr. Musammat Aklima Akter Hely, MBBS

Medical Officer

Department of Gastroenterology

North East Medical College, South Surma, Sylhet.

5. Dr. Nasrin Aktar, MBBS

Registrar

Department of Gastroenterology

North East medical College, South Surma, Sylhet.

6. Dr. Habib Ullah Abir, MBBS

Department of Gastroenterology

North East medical College, South Surma, Sylhet.

\section{Introduction:}

Lower gastrointestinal bleeding (LGIB) is defined as bleeding beyond the ligament of Treitz ${ }^{1}$. It may ranges from occult intestinal bleeding to life treating overt fresh bleeding - haematochezia. Annual hospitalization rate due to LGIB ranges from 20-30 per 100,000 persons $^{2}$. Incidence of lower gastrointestinal bleeding increases with age ie, hospitalization rate with men predominance ${ }^{3}$. Patients with LGIB rarely experience shock and have higher haemoglobin levels ${ }^{4}$. Overall mortality from LGIB is about $2-4 \%$. There is a regional differences in aetiology of LGIB. Diverticulosis coli is common in western Europe and the United states $^{5}$. In western countires, diverticular bleeding, angiodysplaisa, haemorrhoids and polyps constitute $17-56 \%, 3-30 \%, 3-28 \%$ and 2-30\% respectively ${ }^{6}$. Colitis (ie, ischaemic, infectious, inflammatory bowel disease) radiation proctitis, neoplasia and post polypectomy haemorrhages, haemorrhages from upper gastrointestinal sites, Crohn's ileitis, Meckel's diverticulitis and tumor causes $9-21 \%, 11-14 \%, 4-10 \%, 0-11 \%$ and $2-9 \%$ of $\mathrm{LGIB}^{7-9}$. Published report of aetiology of LGIB in our country is not available. With this background this retrospective study was carried out retrieving data from endoscopy records of North East Medical College, Sylhet from January 2016 to December 2018.

\section{Material and Methods:}

This study was retrospective study. Data of consecutive patients undergoing colonoscopic examination presenting with LGIB were retrieved from the registrar of endoscopy of North East Medical College, Sylhet from January 2016 to December 2018. Their demographic information and colonoscopic findings were recorded on a predesigned data sheet. Statistical analysis was done using SPSS version 20. Percentage, mean and SD were calculated. 


\section{Results:}

A total of 309 patients (male $211(68.3 \%)$ and female 98 $(31.7 \%)$ were included in this study (Table I). Age of them varied from five years to 90 years (mean 40.3 years with SD $14.17)$ in this series 54(17.5\%), $120(38.8 \%), 104(34.0 \%)$ and $30(9.7 \%)$ were within up to 25 years, from $26-40$ years, 41-60 years and above 60 years age group.

Table-I: Showing demographic characteristic.

\begin{tabular}{lcc}
\hline Clinical characteristic & Number & Percentage \\
\hline Total & 309 & \\
Male & 211 & 68.3 \\
Female & 98 & 31.7 \\
Age up to 25 years & 54 & 17.5 \\
Age 26-40 years & 120 & 38.8 \\
Age 41-60 years & 105 & 34.0 \\
Age $>60$ years & 30 & 9.7 \\
\hline
\end{tabular}

Causes of LGIB were haemorrhoids 137 (44.33), rectal and colonic growth growth 58 (18.77) rectal and colonic polyps 54 (17.47), anal fissure 38 (12.29), proctitis 18 (5.82), colitis 18(5.82), ileal ulcer and ileitis 34 (11.00) and colonic growth 4(1.29) (Table II).

Table-II: Showing colonoscopic diagnosis.

\begin{tabular}{lllllll}
\hline Aetiology (no) & $\begin{array}{l}\text { Age up to 25 } \\
(\%)\end{array}$ & $\begin{array}{l}\text { 26-40y } \\
(\%)\end{array}$ & $\begin{array}{l}41-60 \mathrm{y} \\
(\%)\end{array}$ & $\begin{array}{l}>60 \mathrm{y} \\
(\%)\end{array}$ & $\begin{array}{l}\text { Male } \\
(\%)\end{array}$ & $\begin{array}{l}\text { Female } \\
(\%)\end{array}$ \\
\hline Fissure 38 & $7(18.42)$ & $18(47.36)$ & $9(23.68)$ & $4(10.52)$ & $24(63.15)$ & $14(36.84)$ \\
Haemorrhoids 137 & $18(13.14)$ & $49(35.76)$ & $54(49.41)$ & $6(4.37)$ & $98(71.53)$ & $39(28.46)$ \\
Rectal ulcer3 & $2(66.66)$ & $1(33.33)$ & 0 & 0 & $2(66.66)$ & $1(33.33)$ \\
Rectal polyp 33 & $4(12.12)$ & $16(48.48)$ & $11(33.33)$ & $2(6.06)$ & $25(75.75)$ & $8(24.24)$ \\
Rectal growth 53 & $5(9.43)$ & $19(38.849)$ & $19(38.849)$ & $10(18.867)$ & $28(52.83)$ & $25(47.17)$ \\
Proctitis (nonspecific) 3 & $2(66.66)$ & 0 & $1(33.33)$ & 0 & $2(66.66)$ & $1(33.33)$ \\
Radiation proctitis 2 & & $1(50.00)$ & $1(50.00)$ & & 0 & $2(100)$ \\
Ulcerative proctitis 13 & $4(30.76)$ & $5(38.46)$ & $4(30.76)$ & 0 & $10(76.92)$ & $3(23.07)$ \\
Colitis (distal),4 & $1(25.0)$ & $1(25.0)$ & 0 & $2(50.0)$ & $3(75.0)$ & $1(25.0)$ \\
pancolitis 4 & $1(25.0)$ & $2(50.0)$ & $1(25.0)$ & 0 & $2(50.0)$ & $2(50.0)$ \\
Nonspecific colitis 14 & $3(21.42)$ & $3(21.42)$ & $7(50.0)$ & $1(7.14)$ & $11(78.57)$ & $3(21.42)$ \\
Crohn's 4 & $1(25.0)$ & $1(25.0)$ & $2(50.0)$ & & $3(75.0)$ & $1(25.0)$ \\
Nonspecific ileal ulcer 17 & $4(23.52)$ & $6(35.29)$ & $7(41.17)$ & 0 & $14(82.35)$ & $3(17.65)$ \\
Tubercular ileal ulcer 3 & $2(66.66)$ & $1(33.33)$ & 0 & 0 & $3(100.0)$ & 0 \\
Caecal ulcers 2 & $1(50.0)$ & 0 & $1(50.0)$ & 0 & $1(50.0)$ & $1(50.0)$ \\
Colonic growth 5 & 0 & $3(60.0)$ & $1(20.0)$ & $1(20.0)$ & $2(40.0)$ & $3(60.0)$ \\
Colonic polyp 21 & $2(9.52)$ & $6(28.57)$ & $12(57.14)$ & $1(4.76)$ & $18(85.71)$ & $3(14.28)$ \\
diverticulum 4 & $1(25.0)$ & 0 & $2(50.0)$ & $1(25.0)$ & $3(75.0)$ & $1(25.0)$ \\
Vascular ectasia 2 & 0 & 0 & $1(50.0)$ & $1(50.0)$ & $2(100.0)$ & 0 \\
normal17 & $4(23.52)$ & $2(11.76)$ & $9(52.94)$ & $1(5.88)$ & $11(64.7)$ & $5(29.41)$ \\
\hline
\end{tabular}

Haemorrhoids was the predominant cause in all age groups and male. Rectal growth was more common among patients age 26 to 60 years. Among male rectal growth was slightly higher than that of female.

\section{Discussion:}

Causes of LGIB are multiple. And severity of LGIB also varies. Most of the LGIB cases have favourable outcome. In our study incidence of LGIB is higher (about 54\%) among younger population (age up to 40 years $)^{10}$. It is consistent with Indian report ${ }^{10}$. But in western countries incidence increases with age reaching hospitalization 200 per 100,000 in the ninth decade $^{2}$. Again mean age of patients with lower GI bleeding in our series is (40.3 years). Mean age of patients with LGI from Pakistan ${ }^{11}$, Nepal $^{12}$ and India ${ }^{10,13,14}$ vary from 35 to 48 years. But in west it is higher varies from 63 to 67 years ${ }^{15}$. In our series males are more affected than females. Reports from Pakistan $^{11}$, Nepal ${ }^{12}$, India ${ }^{10,13,14}$ and China ${ }^{16}$ also showed male predominance.

In our region aetiology of LGIB differs from west. Haemorrhoids, inflammatory bowel disease are common causes and usually present at early age.

In our study commonest cause of LGIB are haemorrhoids which is consistent with report from Pakistan ${ }^{11}$, , Nepal ${ }^{12}$ and India ${ }^{13,14}$. But in western countries diverticular disease, vascular ectasia are the commonest causes ${ }^{2}$. This difference may be due to differences in food habit, ie, high fibre diet taken in our country.

Carcinomna rectum is second commonest cause of LGIB in our series. In west colorectal carcinoma was predominant cause in early 20 th century ${ }^{17}$ when diverticular disease was rare which is the leading cause of LGIB at present. Trend of LGIB etiology is changing. Advancing age, regular CRC screening may influence this change of etiology in the west $^{2}$. Dietary habit, use of NSAID, sedentary life style and obesity, diseases like hypertension, ischaemic heart disease , chronic renal failure, dyslipidaemia are probably associated with this change in western countries.

Radiation proctitis is very low in our series which indicates low prevalence or lower rate of patient getting treatment for carcinoma cervix. But prevalence of radiation proctitis is higher in India ${ }^{10}$.

Tuberculosis is low in our series. But our country is endemic for tuberculosis ${ }^{18}$. Ours is the report from only one centre of Sylhet a city in the north east part of Bangladesh. Again it may not cover all population in the region. Indian reports also shows higher incidence of tuberculosis as etiology of $\mathrm{LGIB}^{10,19}$.

Etiology of LGIB also varies with age of patients ${ }^{16}$. In our series, anal fissure, IBD (ulcerative colitis) constitute majority of LGIB among patients age up to 40 years. Colorectal carcinoma is (slightly) higher among patients of age group 41 to 60 years. It is consistent with reports from India $^{10,19}$ and Jordan ${ }^{20}$.

\section{Conclusion:}

Lower gastrointestinal bleeding is more common among males. Commonest cause of LGIB are internal haemorrhoids, rectal growth, rectal and colonic polyps and anal fissure. Colorectal neoplasm, proctitis, colitis and ileal inflammation and ulcers constitute small part. Prospective multi centre study with large sample size and full work up is recommended in future.

\section{Conflict of Interest: None.}

\section{Acknowledgement:}

I am grateful to the authority of North East Medical College for giving opportunity to do this study. 


\section{References:}

1. Strate LL. Lower GI bleeding: Epidemiology and diagnosis. Gastroenterol Clin North Am. 2005; 34(4):643-664.

https://doi.org/10.1016/j.gtc.2005.08.007

PMid:16303575

2. Longstreth GF. Epidemiology and outcome of patients hospitalised with acute lower gastrointestinal haemorrhages : a population based study. Am J Gastroenterol. 1997; 92(3):419-234.

3. Laine L, Yang H, Chang SC, Datto C. Trend for incidence of hospitalisation and death due to GI complications in The United States from 2001 to 2009. Am J Gastroenterol. 2012; 107:1190-5

https://doi.org/10.1038/ajg.2012.168

PMid:22688850

4. Peura DA, Lanza FL, Gostout CJ, Foutch PG. The American College of Bleeding Registry: Preliminary findings. Am J Gastroenterol. 1997; 92(6): 924-28.

5. Farrell JJ, Friedman LS. Review article: The management of lower gastrointestinal bleeding. Aliment Pharmacol Ther. 2005; 21(11):1281-1298.

https://doi.org/10.1111/j.1365-2036.2005.02485.x

PMid:15932359

6. Tarik SH, Mekhjian G. Gastrointestinal bleeding in older adults. Geriatric Med. 2007; 23: 769-84, vi.

https://doi.org/10.1016/j.cger.2007.07.002

PMid:17923337

7. Longstreth GF. Epidemiology of hospitalisation for acute upper gastrointestinal haemorrhage: a population based study. Am J Gastroenterol.1996; 90(2): 206-10.

8. Velayos FS, Williamson A, Sousa KH. Early predictors of severe lower gastrointestinal bleeding and adverse outcomes: a prospective study. Clin Gastroenterol Hepatol. 2004; 2(6):485-490.

https://doi.org/10.1016/S1542-3565(04)00167-3

9. Al Qahtani AR, Satin R Stern J, Gordon PH. Investigative modalities for massive lower gastrointestinal bleeding. World J Surg. 2002; 26(5): 620-625.

https://doi.org/10.1007/s00268-001-0279-x

PMid:12098057

10. Lakhanpal V, Sharma R, Bodh V, Tahkur S, Sharma N, Sharma Brij. Clinical Spectrum of chronic lower gastrointestinal bleeding in sub-himalays: a study at a tertiary care Hospital of north India. Journal of Digestive endoscopy. 2019; 10(3) : 158-162.

https://doi.org/10.1055/s-0039-3401454
11. Jehangiri AR, Gul R, Hadayat R, Khan AN, Zabiullah KL. Causes of lower gastrointestinal bleeding in colonoscopy. J Ayub Med Coll Abbottabad. 2017; 29 (3):468-71.

12. Umid Kumar Shrestha. Etiological profile, gender difference and age group patterns of 415 patients presenting with lower gastrointestinal bleeding in the western region of Nepal. Journal of Advances in Internal Medicine. 2014;03(02):52-55.

https://doi.org/10.3126/jaim.v3i2.14064

13. Hajare S, Kantamaneni R. Etiological profile of patients with lower gastrointestinal bleeding: A 1-year cross-sectional study. Arch Med Health Sci. 2018;6:300-2.

https://doi.org/10.4103/amhs.amhs_33_17

14. Arpit B, Mehrotra MK, Mowar AB. Etiological profilr of lower gastrointestinal bleeding in a tertiary care hospital in northern India. 2019; 9(11).

https://doi.org/10.36106/ijar/6301547

15. Loffeld RJ, Van der Putten AB. Newly developing diverticular disease of the colon in patients undergoing repeated endoscopic evaluation. J Clin Gastroenterol. 2002;35:205-6.

https://doi.org/10.1097/00004836-200208000-00021

PMid:12172374

16. Bai Y, Peng J, Gao J, Zou DW, Li ZS. Epidemiology of lower gastrointestinal bleeding in China: single-center series and systematic analysis of Chinese literature with 53,951 patients. J Gastroenterol Hepatol. 2011 Apr; 26(4): 678-82.

https://doi.org/10.1111/j.1440-1746.2010.06586.x

PMid:21083610

17. Boley SJ, DiBiase A, Brandt LJ, Sammartano RJ. Lower intestinal bleeding in the elderly. Am J Surg. 1979 Jan; 137(1): 57-64.

https://doi.org/10.1016/0002-9610(79)90011-4

18. Das A, Epidemic situation of tuberculosis in Bangladesh: An overview. South East Asia Journal of public health. 2016; 6(2): 61-2.

https://doi.org/10.3329/seajph.v6i2.31837

19. Goenka MK, Kochhar R, Mehta SK. Spectrum of lower gastrointestinal haemorrhage: an endoscopic study of 166 patients. Indian J of Gastroenterol. 1993; 12(4):129-31.

20. Shennak, M.M., Tarawneh, M.M. Pattern of colonic disease in lower gastrointestinal bleeding in Jordanian patients. Dis Colon Rectum. 1997;40:208-214.

https://doi.org/10.1007/BF02054990

PMid:9075759 